\title{
Longevidade pós-colheita de alpínia [Alpinia purpurata (Vieill.) K. Schum.] tratada com soluções de sacarose e extratos aquosos naturais
}

\begin{abstract}
SANT'ANNA, H.L.S. '; SANTOS, O.S.N. '; SANTOS, C.R.S. '; MARTINS, C.Y.'; SANTOS, M.B. '; ALMEIDA, M.A. ${ }^{1}$; SILVA, F. ${ }^{1 *}$; MARTINS, G.N. ${ }^{3}$; LEDO, C.A.S. ${ }^{2}$

${ }^{1}$ Centro de Ciências Agrárias, Ambientais e Biológica, Universidade Federal do Recôncavo da Bahia/UFR,

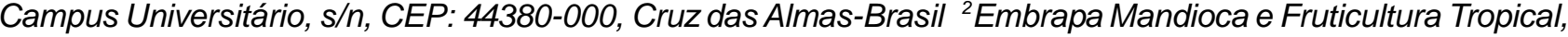

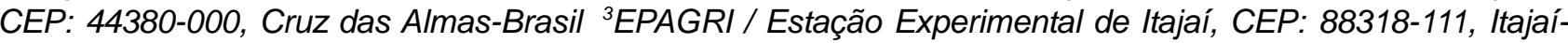
Brasil *franceli@ufrb.edu.br
\end{abstract}

\begin{abstract}
RESUMO: A alpínia (Alpinia purpurata) é uma planta tropical encontrada em diversas regiões do Brasil com excelente potencial para a comercialização como flor de corte. Entretanto, a senescência das hastes pela exaustão da sacarose é um dos principais fatores que afetam a durabilidade comercial, sendo suprimida através da adição de sacarose nas soluções de pulsing. O presente trabalho objetivou avaliar o efeito de extratos aquosos de estévia (Stevia rebaudiana), anis estrelado (Illicium verum) e sacarose em solução de pulsing na manutenção da qualidade pós-colheita de inflorescências de alpínia. Hastes florais uniformizadas em tamanho foram submetidas à solução de pulsing, por 12 horas, nas concentrações de 0,$5 ; 1,0 ; 2,0$ e 3,0\%, tendo água destilada como controle. A melhor qualidade comercial das inflorescências foi obtida quando as hastes foram colocadas em pulsing em extratos de anis estrelado e estévia 1\% e em solução de sacarose $2 \%$, não apresentando diferença estatística entre si. A longevidade total das hastes não foi influenciada pelos tratamentos. A solução de sacarose pode ser substituída pelos extratos das plantas medicinais estudadas, na conservação pós-colheita de inflorescências de alpínia.
\end{abstract}

Palavras-chave: Alpinia purpurata, Stevia rebaudiana, Illicium verum, sacarose

\begin{abstract}
Postharvest longevity of red ginger [Alpinia purpurata (Vieill.) K. Schum.] treated with sucrose solutions and natural water extracts. Red ginger (Alpinia purpurata) is a tropical plant found in several Brazilian regions with excellent potential for commercialization as cut flower. However, the senescence of flower stems due to the exhaustion of sucrose is a major factor that affects commercial durability and is suppressed through addition of sucrose in pulsing solutions. The aim of this work was to evaluate the effect of water extracts from stevia (Stevia rebaudiana), star anise (Illicium verum) and sucrose in pulsing solution on the postharvest quality maintenance of red ginger inflorescences. Flower stems of uniform size were subjected to the pulsing solution for $12 \mathrm{~h}$ at $0.5,1.0,2.0$ and $3.0 \%$ concentrations, with distilled water as control. The best commercial quality of inflorescences was obtained when flower stems were kept in pulsing solutions from $1 \%$ star anise and stevia extracts and in $2 \%$ sucrose solution, not presenting statistical difference. Total longevity of flower stems was not influenced by treatments. Sucrose solution may be replaced by extracts of the studied medicinal plants in the postharvest conservation of red ginger inflorescences.
\end{abstract}

Key words: Alpinia purpurata, Stevia rebaudiana, Illicium verum, sucrose

\section{INTRODUÇÃO}

Alpinia purpurata, também conhecida como alpínia vermelha ou gengibre vermelho, é uma planta tropical herbácea da família Zingiberaceae, encontrada em todas as regiões tropicais do mundo, concentrando-se particularmente na região sudoeste da Ásia (Castro, 1995). As alpínias possuem inflorescência terminal composta por várias unidades morfológicas como pétalas, sépalas, androceu, gineceu, brácteas e raque. A inflorescência é formada por folhas modificadas que consistem de bainhas

Recebido para publicação em 23/11/2008

Aceito para publicação em 25/03/2010

Rev. Bras. PI. Med., Botucatu, v.12, n.3, p.269-277, 2010. 
semelhantes à escamas, denominadas brácteas (Mattiuz, 2003).

Cultivada há muito tempo como planta ornamental em paisagismo, só recentemente seu uso como flor de corte vem se intensificando, devido à durabilidade e beleza das inflorescências, juntamente com o seu florescimento durante 0 ano todo. Entre as Zingiberaceas cultivadas como flor de corte, a alpínia é a mais difundida (Wood, 1995).

Um dos entraves de toda cadeia produtiva das flores tropicais no Brasil é o manuseio póscolheita, o que leva a dificuldades de se adequar à competitividade do mercado internacional. As perdas dos produtos da floricultura chegam, entre a produção e o consumidor final, a índices de 20 a 50\% (Teixeira, 2005).

A senescência em pós-colheita tem como principais causas a exaustão de reservas pela respiração, notadamente de carboidratos a ocorrência de fungos e bactérias que concorrem para a obstrução dos vasos condutores, a produção de etileno e ainda, a perda excessiva de água (Lima et al., 2006). O controle é processo que varia entre espécies e requer a máxima otimização.

Castro (1984) pesquisou tipos de soluções que são normalmente utilizadas na pós-colheita de flores, podendo ser classificadas de acordo com o objetivo de uso em soluções de condicionamento ou pulsing, indução à abertura floral e manutenção das flores.

O pulsing é tratamento rápido de prétransporte ou armazenamento que afeta a fase inicial da vida das flores, prolongando-a mesmo após a transferência para água ou solução de manutenção. Recomenda-se a utilização de soluções que são constituídas, especialmente, por açúcares e germicidas com inclusão, quando necessário, de outros compostos químicos, como inibidores do etileno (Lima et al., 2006; Mattiuz et al., 2005; DiasTagliacozzo et al., 2003).

A sacarose é o carboidrato solúvel mais utilizado nas soluções de condicionamento. Ela viabiliza a absorção de água pelas hastes florais, retardando a senescência e adiando a produção de etileno. Atua como substrato respiratório, suplementando os açúcares naturais, que são rapidamente utilizados após o corte (Van Door, 2001).

Vários autores recomendam a utilização de sacarose como fonte energética para as flores de corte após o período de colheita (Hastenreiter et al., 2006; Silva, 2006; Barbosa et al., 2005; Carneiro et al., 2002), no entanto, altas doses de sacarose combinada a diferentes espécies pode prejudicar a durabilidade comercial das hastes florais, como verificado por Brackmann et al. (2004) em Zinnia elegans; Eason et al. (2001) em Santonia 'Golden Light'; e Moraes et al. (1999) em Strelitzia reginae.
A crescente exigência do mercado por produtos vegetais de qualidade, livres de contaminação por microrganismos e resíduos químicos, vem restringindo o uso de produtos químicos em pós-colheita e, com isso, tem incrementado o desenvolvimento de pesquisas que busquem métodos alternativos para controlar as perdas pós-colheita (Mari \& Guizzardi, 1998).

Uma alternativa é a utilização de compostos secundários encontrados em extratos ou óleos essenciais de plantas medicinais (Schwan-Estrada \& Stangarlin, 2005), que podem apresentar na composição alto teor de sacarose, atividade nematicida, inseticida, antiviral, bactericida e fungicida.

Dentre as plantas medicinais com capacidade de disponibilizar açúcares, está a estévia (Stevia rebaudiana Bert.) que é uma planta originária do Paraguai, conhecida popularmente como capimdoce, erva-adocicada ou erva-doce. Apresenta nas folhas diversos compostos glicosídeos não-calóricos, sendo o mais doce o esteviosídeo, que tem poder adoçante chegando a ser 300 vezes maior que o da sacarose (Lorenzi \& Matos, 2002).

O anis estrelado (Illicium verum L.), originário da China, também é conhecido no Brasil como anis da china ou badiana (Grossman, 2005). Utilizado majoritariamente como erva aromática na doceria/ culinária e na fabricação de bebidas licorosas devido ao poder adoçante, chegando a ser 13 vezes mais ativo que a sacarose. Recentemente, Roopa et al. (2007) identificaram atividade antioxidante seja do óleo essencial e dos extratos em diferentes métodos. Tuan \& llangantileke (1997), analisando a constituição química do anis estrelado, verificaram o trans-anetol como constituinte majoritário (98\%), responsável pelo poder adoçante.

Baseando-se na propriedade adoçante da estévia e do anis estrelado, é que se objetivou avaliar os efeitos de extratos provenientes dessas plantas medicinais e da sacarose em solução de pulsing na manutenção da qualidade pós-colheita de inflorescências de $A$. purpurata.

\section{MATERIAL E MÉTODO}

Inflorescências de alpínia cultivar Red Ginger foram adquiridas em plantio comercial e transportadas ao Laboratório do Núcleo de Agricultura Familiar (NAF) da Universidade Federal do Recôncavo da Bahia, em Cruz das Almas (BA). Nesse trabalho adotou-se o termo hastes florais para o conjunto que compreende caule, folhas e flores. O ponto de colheita comercial foi determinado segundo metodologia desenvolvida por Loges et al. (2005), sendo realizada a colheita no período da manhã entre 6:00 e 8:00 horas.

As hastes foram lavadas, padronizadas em $60 \mathrm{~cm}$ de comprimento, por meio do corte da porção

Rev. Bras. Pl. Med., Botucatu, v.12, n.3, p.269-277, 2010. 
basal com estilete, pesadas individualmente e as inflorescências medidas. Então foram colocadas em solução de pulsing por $12 \mathrm{~h}$. Após esse período as hastes foram retiradas da solução, realizando novo corte na região basal, as quais foram transferidas para vasos de $500 \mathrm{~mL}$ contendo água destilada. A troca de água dos vasos e as avaliações foram realizadas a cada dois dias e, mediante o critério de notas, avaliou-se a durabilidade comercial e longevidade total, e pela determinação da variação de massa fresca, a turgescência das hastes, nos diferentes tratamentos.

Para as soluções de estévia ( $S$. rebaudiana) e anis estrelado (I. verum), extratos aquoso foram obtidos através da metodologia empregada por Iganci et al. (2006), além das soluções contendo sacarose P.A. As concentrações empregadas foram de 0,$5 ; 1,0$; 2,0 e $3,0 \%$.

A cada duas hastes presentes em cada vaso, (numerados previamente) foi atribuída uma nota, reflexo de parâmetros objetivos e bem definidos durante a caracterização física. Nota 0: descarte; Nota 1: aspecto geral ruim, maioria das folhas amarelas e secas, perda de turgescência e queda das brácteas, inflorescência inclinadas; Nota 2: aspecto geral bom, início da perda de turgescência, início do amarelecimento das folhas e Nota 3: aspecto geral excelente, brácteas túrgidas e com brilho e folhas verdes.

Como índice para o período de durabilidade comercial, foi considerado a média igual ou superior a 2,0. A longevidade total correspondeu ao período de dias entre a colheita e o descarte.

Para determinação da variação da massa fresca, as hastes foram pesadas em balança digital. Para isso, foi considerado o valor da primeira pesagem como $100 \%$, peso após a colheita, para as demais pesagens foi empregado a equação $V M F=$ [(pesagem $x$ 100)/1a pesagem], o que possibilitou calcular a variação da massa fresca, expressa em porcentagem.

Durante o experimento as condições de temperatura no laboratório foram monitoradas, apresentando valores médios de $26 \pm 1^{\circ} \mathrm{C}$, com luminosidade oriunda da área externa ao laboratório, sem utilização de luz artificial.

O delineamento experimental foi inteiramente casualizado, num esquema fatorial $3 \times 4+1$, composto dos fatores: três soluções (extrato de estévia, anis estrelado; e sacarose) por quatro concentrações $(0,5 ; 1,0 ; 2,0$ e 3,0\%), mais testemunha (água destilada) com quatro repetições, tendo cada repetição duas hastes florais. Classificar-se-á como pulsing a interação entre os fatores soluções e concentrações.

Os dados foram submetidos à análise de variância. As médias dos tratamentos das soluções foram comparadas pelo teste de Tukey a $5 \%$ de probabilidade e para as médias das concentrações foram ajustadas equações de regressão polinomial. Foi utilizado o teste de Dunnett a 5\% de probabilidade para comparação da testemunha com os demais tratamentos.

\section{RESULTADO E DISCUSSÃO}

Conforme a distribuição de frequência (Figura 1) os comprimentos das inflorescências variaram de 15 a $23 \mathrm{~cm}$, sendo que $65 \%$ estiveram no intervalo de 18 a $20 \mathrm{~cm}$, com o tamanho médio de $18,85 \pm 1,75$. Com relação ao peso inicial, as hastes pesaram entre 55,47 e 141,62 g, e a média das 104 observações foi de $88,85 \pm 18,18 \mathrm{~g}$, com maior freqüência na faixa de 70 a $109 \mathrm{~g}$. O peso final variou entre 3,47 e 93,58 g, e a média foi de 36,16 $\pm 25,48$.

Apesar do cuidado na padronização das hastes existiu variação expressiva na biomassa inicial, o qual pode ter influenciado o alto valor do coeficiente de variação $(20,97)$ para a durabilidade comercial (Tabela 1).

A significância do efeito das soluções e das concentrações (pulsing) na durabilidade comercial e longevidade total em hastes de alpínia são mostradas na Tabela 1.

Nota-se que não houve diferença significativa das soluções (extrato de estévia, anis estrelado e sacarose) na durabilidade comercial das hastes $(p<0,05)$, evidenciando a atividade dos extratos das plantas medicinais, neles possibilitando que as hastes apresentem características qualitativas pós-colheita semelhantes estatisticamente às tratadas em solução de sacarose, independente da concentração utilizada.

Para longevidade total, foi observado efeito significativo, sendo justificado pela diferenciação das médias encontradas entre o extrato de estévia e as demais soluções, independente da concentração utilizada. $O$ extrato de anis estrelado e a sacarose proporcionaram longevidade total de 19,0 e 18,5 dias, respectivamente, sendo superior 3,5 e 3,0 dias ao extrato de estévia (15,5 dias).

Analisando de forma independente as concentrações em que as hastes foram submetidas, foi verificada diferença estatística significativa para a durabilidade comercial e longevidade total, sendo a concentração de $1,0 \%$ a que proporcionou melhor resultado.

O fatorial soluções vs concentrações apresentou interação significativa, indicando que a relação existente entre as soluções de condicionamento e as diferentes concentrações influenciaram os padrões de durabilidade comercial e longevidade total das hastes florais.

Podem ser verificados na Figura 2, os níveis de significâncias obtidos, bem como as melhores equações de regressão ajustadas e os coeficientes

Rev. Bras. PI. Med., Botucatu, v.12, n.3, p.269-277, 2010. 

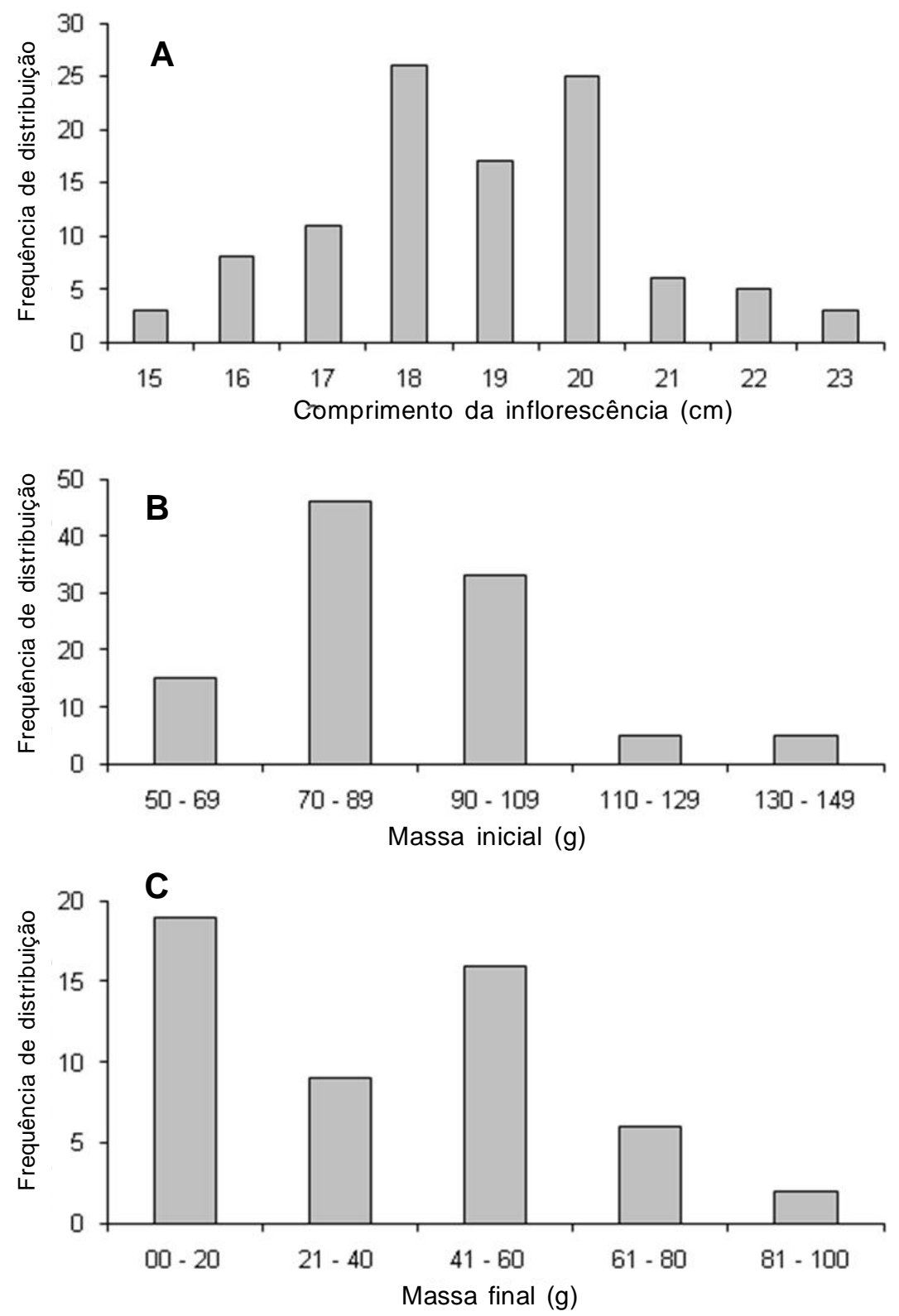

FIGURA 1. Distribuição de frequência do: A. comprimento de inflorescência (cm); B. massa inicial $(\mathrm{g})$ e C. massa final (g) de 104 hastes de alpínia.

TABELA1. Resumo da análise de variância da durabilidade comercial e longevidade total em hastes de alpínia.

\begin{tabular}{lccc}
\hline \multicolumn{1}{c}{ Fontes de variação } & GL & \multicolumn{2}{c}{ Quadrado médio } \\
\cline { 3 - 4 } & & Durabilidade comercial & Longevidade to tal \\
\hline Soluções $^{1}$ & 2 & $7,58^{\text {ns }}$ & $54,33^{*}$ \\
Concentrações $^{1}$ & 3 & $16,55^{*}$ & $17,22^{*}$ \\
Soluções x Concentrações $^{1}$ & 6 & $19,80^{\star}$ & $31,22^{\star}$ \\
Fatorial vs Testemunha $^{2}$ & 1 & $13,56^{*}$ & $1,25^{*}$ \\
\hline Erro & & $\mathbf{3 , 3 8}$ & $\mathbf{5 , 4 3}$ \\
\hline \multicolumn{2}{c}{$\mathrm{CV}(\%)$} & $\mathbf{2 0 , 9 7}$ & $\mathbf{1 3 , 2 9}$ \\
\hline
\end{tabular}

${ }^{1}$ Teste de Tukey; ${ }^{2}$ Teste de Dunett; $n s:$ Não significativo ao nível de $5 \%$ de probabilidade; * Significativo ao nível de $5 \%$ de probabilidade. 

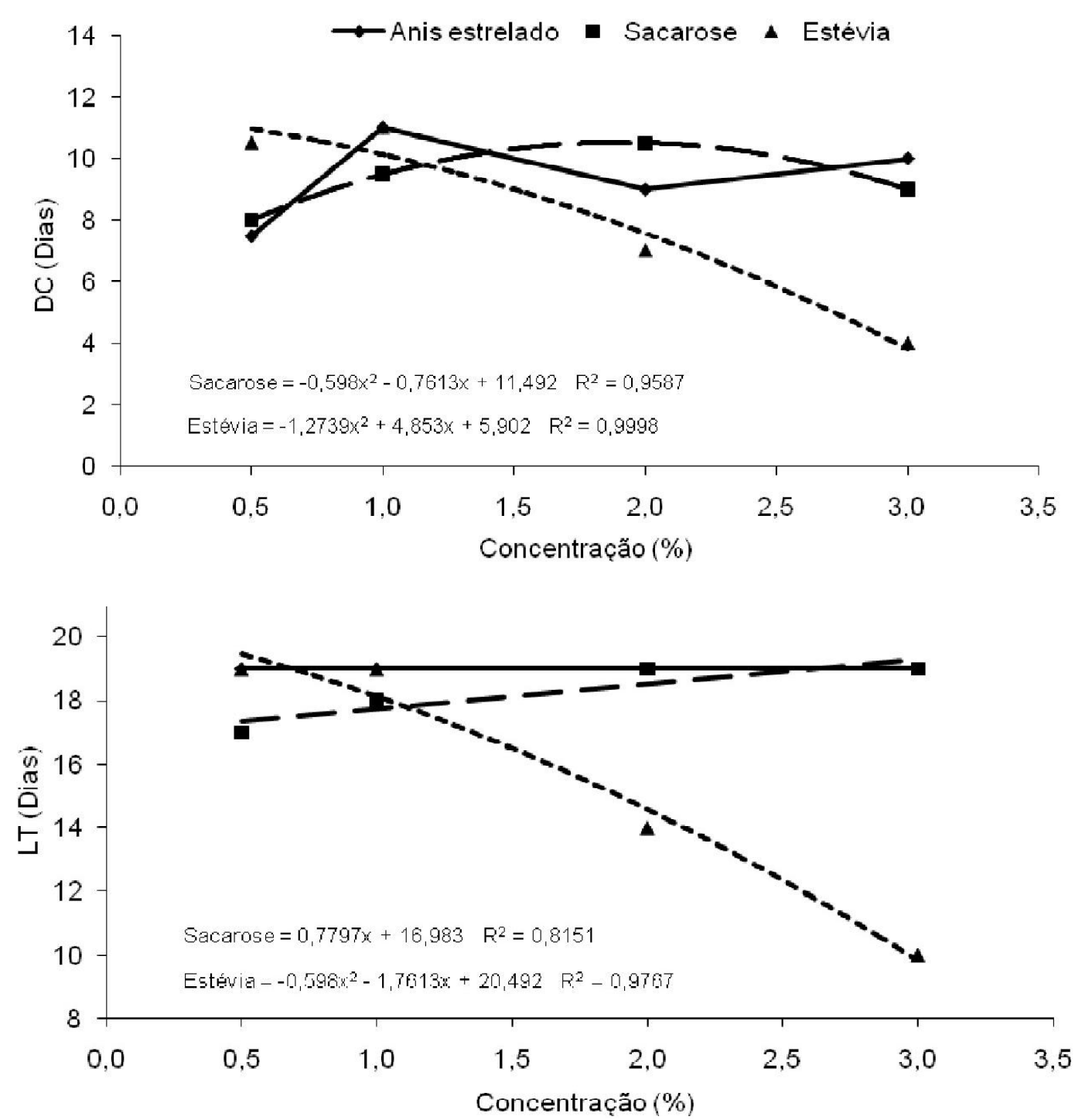

FIGURA2. Durabilidade comercial (DC) e longevidade total (LT) de hastes de alpínia submetidas a tratamentos de pulsing.

de determinação, com elevado valor, para essa interação.

Para o extrato de anis estrelado não foi possível ajustar equação com significado biológico que representasse os efeitos relacionados com as concentrações para durabilidade comercial e longevidade total, entretanto, as hastes submetidas ao extrato na concentração de $1,0 \%$ foram as que apresentaram maior durabilidade comercial, de 11 dias, não sendo verificado efeito significativo para longevidade total que foi de 19,0 dias em todas as concentrações.

Na sacarose foi ajustada equação polinomial de segundo grau para durabilidade comercial e de primeiro grau para longevidade total. Esse pulsing aumentou a durabilidade comercial, tendo como ponto de máxima eficiência na concentração de 2,0\%, possibilitando que as mesmas permanecessem nos padrões de comercialização por 10,5 dias, entretanto, concentrações superiores apresentaram escurecimento das brácteas, comprometendo a qualidade das hastes. Diferentemente, a longevidade total correspondeu positivamente com o aumento na concentração, de 17 (0,5\%) para 19 dias (3,0\%).

Analisando os efeitos do extrato de estévia nas diferentes concentrações sobre a durabilidade comercial e longevidade total das hastes de alpínia foi possível ajustar equação polinomial quadrática. A concentração de $1,0 \%$ foi a que proporcionou melhor durabilidade comercial, 11 dias de vida em vaso.

Contudo, com o aumento na concentração da solução de pulsing houve redução significativa na qualidade das hastes, atingindo características mínimas de comercialização em 4 dias na máxima concentração, caracterizando efeito fitotóxico pelo alto teor de açúcares da estévia (Portugal, 2006). A 
concentração até $1,0 \%$ foi a que possibilitaram maior longevidade total às hastes, de 19 dias, apresentando comportamento redutivo com o aumento da concentração atingindo 10 dias da colheita até o descarte na concentração máxima (Figura 1).

Dias-Tagliacozzo et al. (2003) observaram aumento na durabilidade comercial de hastes de alpínia cultivar Red Ginger tratadas com sacarose $1 \%+200$ ppm de ácido cítrico, em dois dias quando comparadas com as hastes tratadas em água destilada. O aumento na concentração de 2,0\% para $20 \%$ de sacarose em solução pulsing por Silva (2006) fez com que as hastes de Alpinia var. Pink Ginger apresentassem incremento significativo na durabilidade comercial e longevidade total de aproximadamente em três dias.

Contudo, Ferreira et al. (2008) verificaram maior durabilidade comercial de hastes de alpínia cultivar Red Ginger tratadas com pulsing de sacarose $2 \%$ ( 15,5 dias), tendo a qualidade pós-colheita decaído com o acréscimo de sacarose, chagando a 4 dias na concentração $8 \%$, redução de quatro vezes.

$\mathrm{Na}$ comparação do fatorial vs testemunha, utilizando o teste de Dunnett a $5 \%$ de probabilidade, verificou-se diferença estatística $(p<0,05)$ para a durabilidade comercial (DC) e longevidade total (LT) (Tabela 2).

As hastes que foram tratadas com as soluções de anis estrelado e estévia 1,0\% tiveram aumento de 4 dias na durabilidade comercial em relação às hastes tratadas com água destilada, ou seja, essas hastes permaneceram por 11 dias com aspecto visual aceitável para comercialização.
Apesar de não haver diferença estatística para os demais tratamentos, faz-se necessário considerar os efeitos benéficos daqueles que apresentaram valores de durabilidade comercial superior a 7,0 dias (testemunha), pois analisando do ponto de vista de benefício e distribuição das hastes no mercado consumidor, quanto mais tempo (dias) com excelente qualidade pós-colheita, melhor.

Em relação a longevidade total, só o extrato de estévia 3,0\% foi que diferiu do tratamento, apresentando valor inferior, provavelmente provocado pelo efeito fitotóxico da concentração dos açúcares na solução.

Segundo Halevy (1981), açúcares translocados das soluções conservantes acumulamse nas flores, aumentando a concentração osmótica, melhorando a capacidade de absorção e manutenção da turgescência das pétalas e favorecendo, desse modo, o balanço hídrico das flores de corte.

A análise de variância para a variação da massa fresca (\%) demonstra que não houve efeito significativo das soluções e das concentrações na manutenção do teor de água nas hastes $(p>0,05)$. Entretanto, a interação entre eles foi significativa a $5 \%$ de probabilidade pelo teste de Tukey.

$\mathrm{Na}$ Figura 3, verifica-se o resultado dessa interação com características semelhante à durabilidade comercial e longevidade total das hastes florais de A. purpurata, confirmada por Gonzaga et al. (2001) que afirmaram ser o balanço hídrico fator determinante na longevidade dos órgãos das plantas e a deficiência de água no organismo acelera a senescência.

TABELA 2. Médias de durabilidade comercial (DC) e longevidade total (LT) em hastes de alpínia submetidas à solução de pulsing em comparação com a testemunha.

\begin{tabular}{|c|c|c|c|}
\hline \multicolumn{2}{|c|}{ Tratamentos } & DC & LT \\
\hline Solução & Concentração (\%) & \multicolumn{2}{|c|}{ 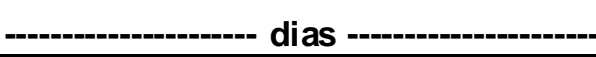 } \\
\hline \multirow{4}{*}{ Anis estrelado } & 0,5 & $7,50 \mathrm{~b}$ & $19,00 \mathrm{a}$ \\
\hline & 1,0 & $11,00 \mathrm{a}$ & $19,00 \mathrm{a}$ \\
\hline & 2,0 & $9,00 \mathrm{~b}$ & $19,00 \mathrm{a}$ \\
\hline & 3,0 & $10,00 \mathrm{~b}$ & $19,00 \mathrm{a}$ \\
\hline \multirow{4}{*}{ Sacarose } & 0,5 & $8,00 \mathrm{~b}$ & $17,00 \mathrm{a}$ \\
\hline & 1,0 & $9,50 \mathrm{~b}$ & $18,00 \mathrm{a}$ \\
\hline & 2,0 & $10,50 \mathrm{~b}$ & $19,00 \mathrm{a}$ \\
\hline & 3,0 & $9,00 \mathrm{~b}$ & $19,00 \mathrm{a}$ \\
\hline \multirow{4}{*}{ Estévia } & 0,5 & $10,50 \mathrm{~b}$ & $19,00 \mathrm{a}$ \\
\hline & 1,0 & $11,00 \mathrm{a}$ & $19,00 \mathrm{a}$ \\
\hline & 2,0 & $7,00 \mathrm{~b}$ & $14,00 \mathrm{a}$ \\
\hline & 3,0 & $4,00 \mathrm{~b}$ & $10,00 \mathrm{~b}$ \\
\hline Testemunha & & $7,00 \mathrm{~b}$ & $17,00 \mathrm{a}$ \\
\hline
\end{tabular}

Valores seguidos de letras iguais na mesma coluna, não diferem entre si, pelo teste de Dunnett a $5 \%$ de probabilidade.

Rev. Bras. Pl. Med., Botucatu, v.12, n.3, p.269-277, 2010. 


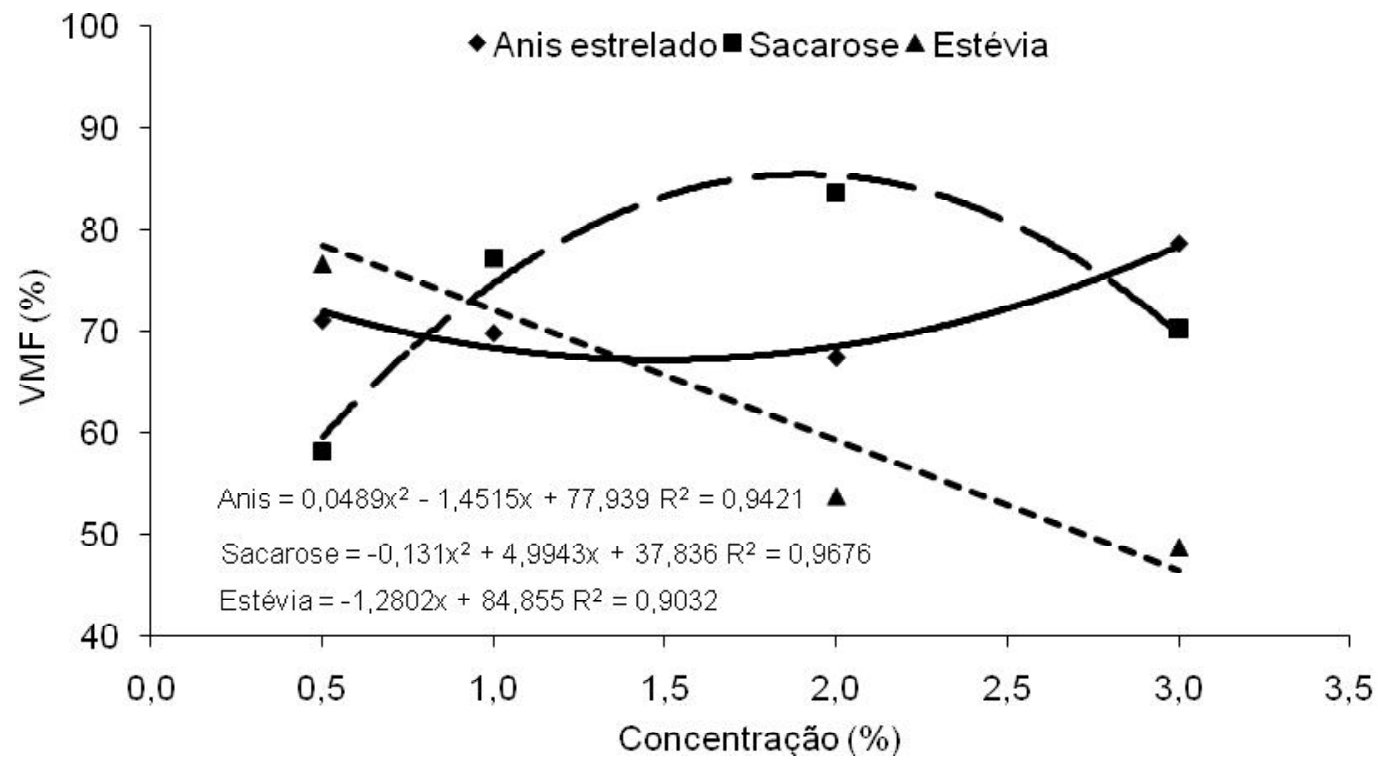

FIGURA 3. Variação da massa fresca em hastes de alpínia submetidas a tratamentos de pulsing.

A análise de regressão dos resultados demonstra que o extrato de anis estrelado 3,0\% possibilitou máximo acúmulo de massa fresca, sendo justificado por maior absorção de água pelas hastes. Altos índices de hidratação são, em geral, associados ao aumento de vida de vaso em flores de corte (Moraes et al., 1999).

$\mathrm{Na}$ avaliação realizada para a sacarose, observa-se que a concentração de $2,0 \%$ permitiu que as hastes apresentassem o maior aumento da massa fresca, dentre todos os tratamentos, apresentando efeito depressivo a partir desse ponto, originando uma equação quadrática negativa com coeficiente de determinação de $96 \%$.
Com a utilização do extrato de estévia podese observar decréscimo linear de $37 \%$ na massa fresca, entre a menor e maior concentração, indicando menor absorção de água por essas hastes. Barbosa et al. (2005) observaram redução na absorção de água em inflorescências de lírio com o aumento de sacarose em solução de pulsing. Soluções aquosas concentradas em açúcares podem apresentar elevado potencial osmótico, gerando a desidratação dos tecidos através da retirada de água pela solução hipertônica. Moraes et al. (1999) observaram que a sacarose de 1 e $2 \%$ na solução de vaso é responsável pela plasmólise e morte do tecido de folhas de rosa de corte.

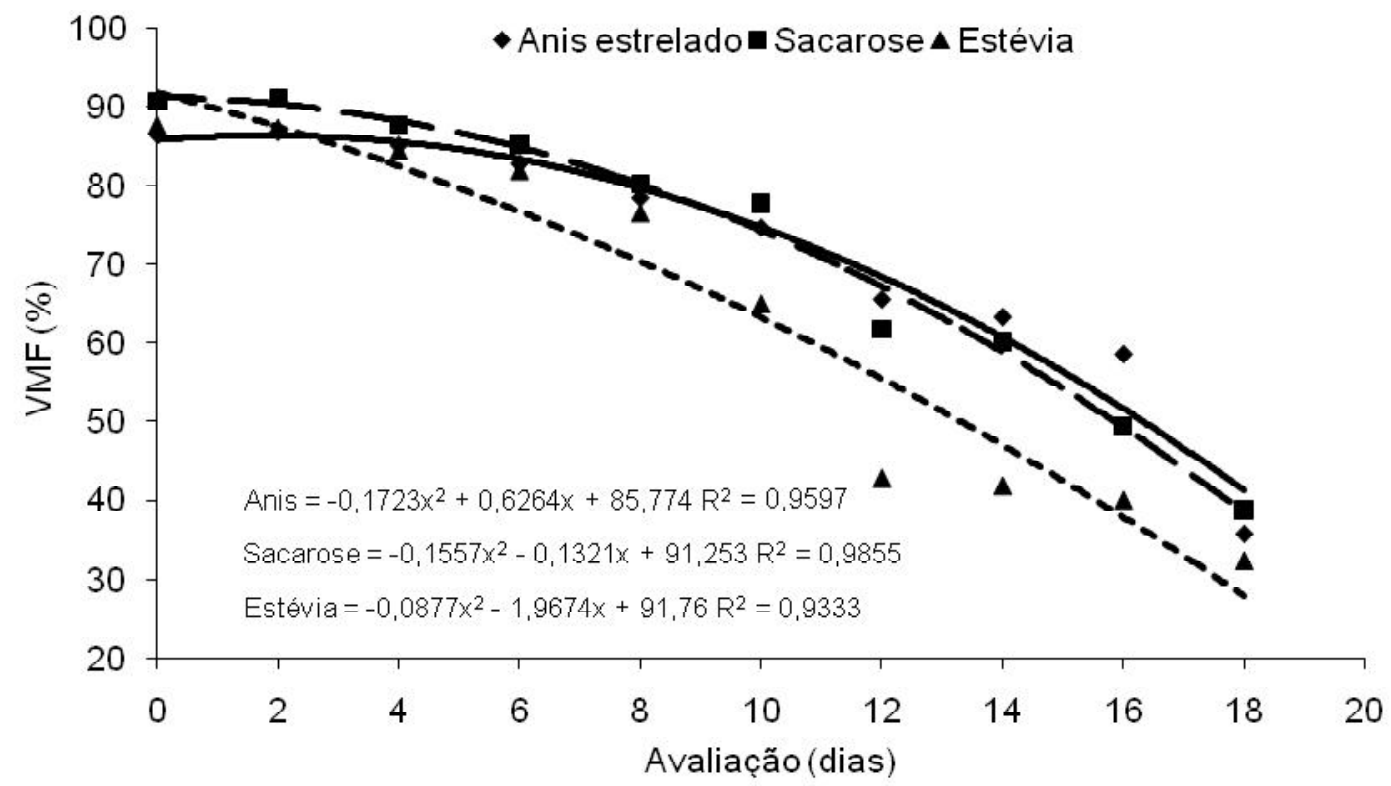

FIGURA4. Variação da massa fresca em hastes de alpínia após serem submetidas ao pulsing ao longo do período (dias) do experimento. 
TABELA 3. Massa fresca final (\%) das hastes florais de alpínia submetidas à solução de pulsing em comparação com a testemunha.

\begin{tabular}{ccc}
\hline \multicolumn{2}{c}{$\begin{array}{c}\text { Tratamentos } \\
\text { Solução }\end{array}$} & $\begin{array}{c}\text { Massa fresca final } \\
(\%)\end{array}$ \\
\hline \multirow{3}{*}{ Concentração (\%) } & $64,37 \mathrm{~b}$ \\
& 0,5 & $55,05 \mathrm{~b}$ \\
& 1,0 & $62,38 \mathrm{~b}$ \\
Sacarose & 2,0 & $53,40 \mathrm{a}$ \\
& 3,0 & $75,88 \mathrm{c}$ \\
& 0,5 & $57,12 \mathrm{a}$ \\
& 1,0 & $41,19 \mathrm{a}$ \\
Estévia & 2,0 & $56,69 \mathrm{~b}$ \\
& 3,0 & $49,26 \mathrm{a}$ \\
& 0,5 & $39,52 \mathrm{a}$ \\
& 1,0 & $64,40 \mathrm{c}$ \\
Testemunha & 2,0 & $89,32 \mathrm{c}$ \\
\hline
\end{tabular}

Valores seguidos de letras iguais na mesma coluna, não diferem entre si, pelo teste de Dunnett a $5 \%$ de probabilidade.

Avaliando a diminuição da massa fresca (\%) das hastes florais ao longo do experimento, observa-se que houve diferença estatística gerada pelos tratamentos utilizados, acentuando-se a partir do oitavo dia após a aplicação de pulsing (Figura 4), sendo possível ajustar equações quadráticas para todos os tratamentos, com altos coeficientes de determinação.

As hastes tratadas com as soluções de anis estrelado, sacarose e estévia tiveram redução de 58,$62 ; 57,23$ e $63,07 \%$, respectivamente, na massa fresca das hastes.

Comparando as hastes que foram submetidas ao pulsing com as mantidas em água destilada, pode-se verificar que houve diferença significativa pelo teste de Dunett $(p<0,05)$ na massa fresca final. As hastes acondicionadas por 12 horas em água destilada apresentaram no término do experimento valores médios para peso final de $35,93 \mathrm{~g}$, redução de $48,94 \%$ do peso inicial.

A Tabela 3 demonstra que os pulsing com sacarose $0,5 \%$ e estévia 2,0 e $3,0 \%$ foram os que possibilitaram maiores perda de massa fresca pelas hastes, ou seja, houve maior desidratação dos tecidos. Esses resultados reforçam os encontrados para durabilidade comercial (Tabela 2 ), onde esses tratamentos reduziram o tempo de vida de vaso das hastes. Segundo DiasTagliacozzo et al. (2005), essa perda deve-se ao processo de transpiração e também à redução da condutividade de água, durante o processo de senescência da haste flora.

\section{CONCLUSÃO}

Os extratos naturais das plantas medicinais Stevia rebaudiana e Illicium verum podem ser indicadas na conservação pós-colheita de inflorescências de alpínia.

\section{REFERÊNCIA}

BARBOSA, J.G. et al. Longevidade de inflorescências de lírio, de diferentes estádios de colheita, prétratadas com sacarose e tiossulfato de prata (STS). Ciência Rural, v.36, n.1, p.99-104, 2005.

BRACKMANN, A. et al. Qualidade de Zinnia elegans 'Scarlet' em soluções conservantes com sacarose. Revista Brasileira Agrociência, v.10, n.1, p.127-9, 2004.

CARNEIRO, T.F. et al. Influência da sacarose e do corte da base na longevidade de inflorescências de Zinnia elegans. Pesquisa Agropecuária Brasileira, v.37, p.1065-70, 2002.

CASTRO, C.E.F. Inter-relação das famílias das Zingiberales. Revista Brasileira de Horticultura Ornamental, v.1, n.1, p.2-11, 1995.

CASTRO, C.E.F. Tratamento químico pós-colheita e critérios de 4 avaliações da qualidade de cravo (Dianthus caryophyllus L.) CV. Scania Red Sim. 1984. 139p. Dissertação (Mestrado - Área de concentração Agronomia) - Escola Superior de Agricultura Luiz de Queiroz, Universidade de São Paulo, Piracicaba.

DIAS-TAGLIACOZZO, G.M.; ZULLO, M.A.; CASTRO, C.E.F. Caracterização física e conservação pós-colheita 
de alpínia. Revista Brasileira de Horticultura Ornamental, v.9, n.1, p.17-23, 2003.

DIAS-TAGLIOCOZZO, GM.; GONÇALVES, C.; CASTRO, C.E.F. Manutenção da qualidade pós-colheita de lírio. Revista Brasileira Horticultura Ornamental, v.11, n.1, p.29-34, 2005.

EASON, J.R. et al. Postharvest characteristics of Santonia 'Golden Lights' a new hybrid cut flower from Sandersonia aurantiaca x Littonia modesta. Postharvest Biology and Technology, v.22, p.93-7, 2001.

FERREIRA, L.D.B. et al. Durabilidade de inflorescência de Alpinia purpurata var. Red Guinger, tratradas com solução de sacarose. Pesquisa Agropecuária Tropical, v.38, n.3, p.164-8, 2008.

GONZAGA, A.R. et al. Longevidade pós-colheita de inflorescências de girassol afetada por nitrato de prata e sacarose. Revista Brasileira de Horticultura Ornamental, v.7, n.1, p.73-7, 2001.

GROSSMAN, L. Óleos essenciais na culinária, cosmética e saúde. São Paulo, Optinline, 2005. 300p.

HALEVY, A.H.; MAYAK, S. Senescence and postharvest physiology of cut flowers. Part. 2. Horticultural Reviews, v.3, p.59-143, 1981.

HASTENREITER, F.A. et al. Longevidade pós-colheita de flores de Oncidium varicosum (Orchidaceae). Semina, v.27, n.1, p.27-34, 2006.

IGANCI, J.R.V. et al. Efeito do extrato aquoso de diferentes espécies de boldo sobre a germinação e índice mitótico de Allium cepa L. Arquivos do Instituto Biológico, v.73, n.1, p.79-82, 2006.

LIMA, J.D.; MORAES, W.S.; SILVA, C.M. Tecnologia póscolheita de flores de corte. São Paulo: Instituto Biológico, 2006. 7p. Disponível em: <http://www.biologico. sp.gov.br/rifib/XIVRifib/lima.pdf>. Acesso em: 30 jul. 2007. LOGES, $\bar{V}$. et al. Colheita, pós-colheita e embalagem de flores tropicais em Pernambuco. Horticultura Brasileira, v.23, n.3, p.699-702, 2005.

LORENZI, H.; MATOS, F.J.A. Plantas medicinais do Brasil: nativas e exóticas. Nova Odessa: Instituto Plantarum, 2002. 512p.

MARI, M.; GUIZZARDI, M. The post harvest phase: emerging technologies for the control of fungal diseases. Phytoparasitica, v.26, n.1, p.59-66, 1998.
MATTIUZ, C.F.M. et al. Efeito de agentes químicos na conservação pós-colheita de inflorescências de Alpinia purúrata (Veill) K. Schum. Revista Brasileira de Horticultura Ornamental, v.11, n.1, p.35-42, 2005.

MATTIUZ, C.F.M. Fisiologia pós-colheita de Inflorescência de Alpinia purpurata (Vieill) K. Schum. 2003. 124p. Tese (Doutorado em Agronomia) - Faculdade de Ciências Agrárias e Veterinárias do Campus de Jaboticabal-Unesp, Jaboticabal.

MORAES, P.J. et al. Efeito da refrigeração e do condicionamento em sacarose sobre a longevidade de inflorescências de Strelitzia reginae Ait. Revista Brasileira de Horticultura Ornamental, v.5, n.2, p.1516, 1999.

PORTUGAL, E.P. Influência de fungos micorrízicos arbusculares, sistemas de cultivo e parâmetros póscolheita na concentração de esteviosídeos e desenvolvimento de Stevia rebaudiana (Bert.) Bertoni. 2006. 144p. Tese (Doutorado) - Universidade Estadual de Campinas, Faculdade de Engenharia Agrícola, Campinas. ROOPA, A.P. et al. Star-anise (Illicium verum) and black caraway (Carum nigrum) as natural antioxidants. Food Chemistry, v.104, n.1, p.59-66, 2007.

SCHWAN-ESTRADA, K.R.F.; STANGARLIN, J.R. Extratos e óleos essenciais de plantas medicinais na indução de resistência. In: CAVALCANTI, L.S. et al. Indução de resistência em plantas a patógenos e insetos. Piracicaba: Fealq, 2005. p.125-32.

SILVA, A.T.C. Manejo pós-colheita de Alpinia purpurata (Vieill) K. Schum (Zingiberaceae). 2006. 105p. Dissertação (Mestrado em Agronomia: Produção vegetal) - Universidade Federal de Alagoas, Centro de Ciências Agrárias, Rio Largo. TEIXEIRA, M.C.F. Curso prático de pós-colheita para flores tropicais. In:ANTUNES, M.G. Floricultura em Pernambuco. Recife: SEBRAE, 2005. p.11-5.

TUAN, D.Q.; ILANGANTILEKE, S.G. Liquid $\mathrm{CO}_{2}$ extraction of essencial oil fron star anise fruits (Illicium verum $\mathrm{H}$.) Journal of Food Enginering, v.31, p.47-57, 1997.

VAN DOOR, W.G. Role of carbohydrates in flower senescence: a survey. Acta Horticulturae, v.543, n.1, p.179-83, 2001.

WOOD, T. Ornamental Zingiberaceae. Revista Brasileira de Horticultura Ornamental, v.1, n.1, p.12-3, 1995. 